\title{
Hospitalizations for Respiratory Problems and Exposure to Industrial Emissions in Children
}

\author{
Rémi Labelle ${ }^{1}$, Allan Brand ${ }^{2}$, Stéphane Buteau ${ }^{2,3}$ \& Audrey Smargiassi ${ }^{2,4}$ \\ ${ }^{1}$ Université de Montréal. Département de Santé Environnementale et de Santé au Travail, Montréal, Québec, \\ Canada \\ ${ }^{2}$ Institut National de Santé Publique du Québec (INSPQ), Canada \\ ${ }^{3}$ Department of Medecine, McGill University, Montréal, Québec, Canada \\ ${ }^{4}$ Chaire sur la pollution de l'air, les changements climatiques et la santé, en partenariat avec la Direction de \\ Santé publique de l'Agence de la santé et des services sociaux de Montréal et l'INSPQ, Université de Montréal, \\ Montréal, Québec, Canada \\ Correspondence: Audrey Smargiassi, Chaire sur la pollution de l'air, les changements climatiques et la santé, en \\ partenariat avec la Direction de Santé publique de l'Agence de la santé et des services sociaux de Montréal et \\ l’INSPQ, Université de Montréal, Montréal, Québec, Canada. E-mail: audrey.smargiassi@umontreal.ca
}

Received: January 23, 2015 Accepted: February 16, 2015 Online Published: March 30, 2015

doi:10.5539/ep.v4n2p77 URL: http://dx.doi.org/10.5539/ep.v4n2p77

\begin{abstract}
Industrial activities such as metal smelting, petroleum refining, and open mining emit air pollutants that can affect the health of surrounding communities. Few studies have assessed respiratory effects of acute exposure to industrial air emissions in children. In this study, we examined the association between daily exposure to air emissions from an industrial complex and hospitalizations for respiratory problems of children living nearby using a case crossover design. We used hospitalizations for respiratory problems of children under 5 years old living within $7.5 \mathrm{~km}$ of the industrial complex from January 1, 2001 to December 31, 2010. Pollutant exposure was estimated using daily mean and maximum concentrations of $\mathrm{SO}_{2}$ and $\mathrm{PM}_{2.5}$ at fixed monitoring stations located near the complex. We also calculated the daily percentage of hours that a child's residence was downwind of the industrial complex as an indicator of exposure to emissions. Odds-ratios were adjusted for temperature, relative humidity and wind speed, and calculated using conditional logistic regressions, reported by increases of interquartile range. A significant positive association was found between hospitalization for asthma or bronchiolitis and the percentage of hours downwind (OR: 1.11,95\% CI=1.01-1.22) but large statistical variability was noted for associations with all three exposure metrics (OR maximum $\mathrm{SO}_{2}$ levels: $1.06,95 \%$ $\mathrm{CI}=0.98-1.15$; OR daily maximum $\mathrm{PM}_{2.5}$ levels: $0.97,95 \% \mathrm{CI}=0.86-1.09$ ). The results suggest that exposure to the mixture of air pollutant emissions from an industrial complex may induce respiratory health problems in children residing nearby.
\end{abstract}

Keywords: emissions, downwind exposure, case-crossover, odds-ratios, $\mathrm{PM}_{2.5}, \mathrm{SO}_{2}$

\section{Introduction}

Few studies have assessed the respiratory effects of exposure to air emissions in children from various types of industries including metal smelters, cement plants, power plants, petrochemical industries, open mining or wood processing plants (Aekplakorn et al., 2003; Bertoldi et al., 2012; Deger et al., 2012; Liu, Lessner, and Carpenter, 2012; Pless-Mulloli, Howell, and Prince, 2001; Rusconi et al., 2011; Smargiassi et al., 2009). Most studies that assessed the effects of industrial air emissions used a cross-sectional design and usually evaluated the respiratory outcome using a questionnaire. These studies have found some associations between respiratory health outcomes, e.g. increased respiratory symptoms, emergency department visits and hospitalizations or decreased pulmonary functions in children, and exposure to industrial air emissions. Nonetheless, only a few studies assessed the respiratory effects of short term exposure to industrial emissions in children (e.g. Aekplakorn et al., 2003; Lewin, Buteau, Brand, Kosatsky, and Smargiassi, 2013; Smargiassi et al., 2009).

The objective of the present study was to estimate the association between daily levels of sulphur dioxide $\left(\mathrm{SO}_{2}\right)$, fine particles $\left(\mathrm{PM}_{2.5}\right)$ and the percentage of daily hours downwind from an industrial complex with an aluminum 
smelter in the Saguenay region of Quebec, Canada and the hospitalizations of children aged 0 to 4 years old for asthma, bronchiolitis and other respiratory causes living in proximity to the industrial complex.

\section{Methods}

\subsection{Study Period, Area and Population}

The study area was located in the Saguenay region of the province of Quebec (Canada).It was centered on three point source emissions (referred to as the industrial complex) near residential neighborhoods. The first emission source (A), i.e. a cast house, emitted, in 2012, 7569 tons of $\mathrm{SO}_{2}$ and 1413 tons of $\mathrm{PM}_{2.5}$ (Environment Canada, 2013). The Söderberg process was used in the past at this plant, and air pollutant emissions were larger (Alain et al., 2011). Emission point B (alumina production plant) emitted much less than point A (86 tons of $\mathrm{SO}_{2}$ and 151 tons of $\mathrm{PM}_{2.5}$ ) in 2012 (Environment Canada [EC], 2013). The third plant, emission point $\mathrm{C}$ (an iron smelter) emitted in 2012, 639 tons of $\mathrm{SO}_{2}$ and 17 tons of $\mathrm{PM}_{2.5}$ (EC, 2013). Another industry is also present in the area of study, a paper mill that emitted less pollutant than the industrial complex: in 2012 , it emitted 83 tons of $\mathrm{PM}_{2.5}$ (EC, 2013). The study area was defined as the area within a buffer of $7.5 \mathrm{~km}$ centered on the industrial complex that included the three emission point sources (see Figure 1 for the location of the industrial complex). The location of the industrial complex was defined as the point between the three emission sources weighted by total emissions of $\mathrm{SO}_{2}$ and $\mathrm{PM}_{2.5}$ from each source during the study period. Approximately 6985 children aged under 5 year old lived in the area in 2011 (Statistics Canada, 2012).

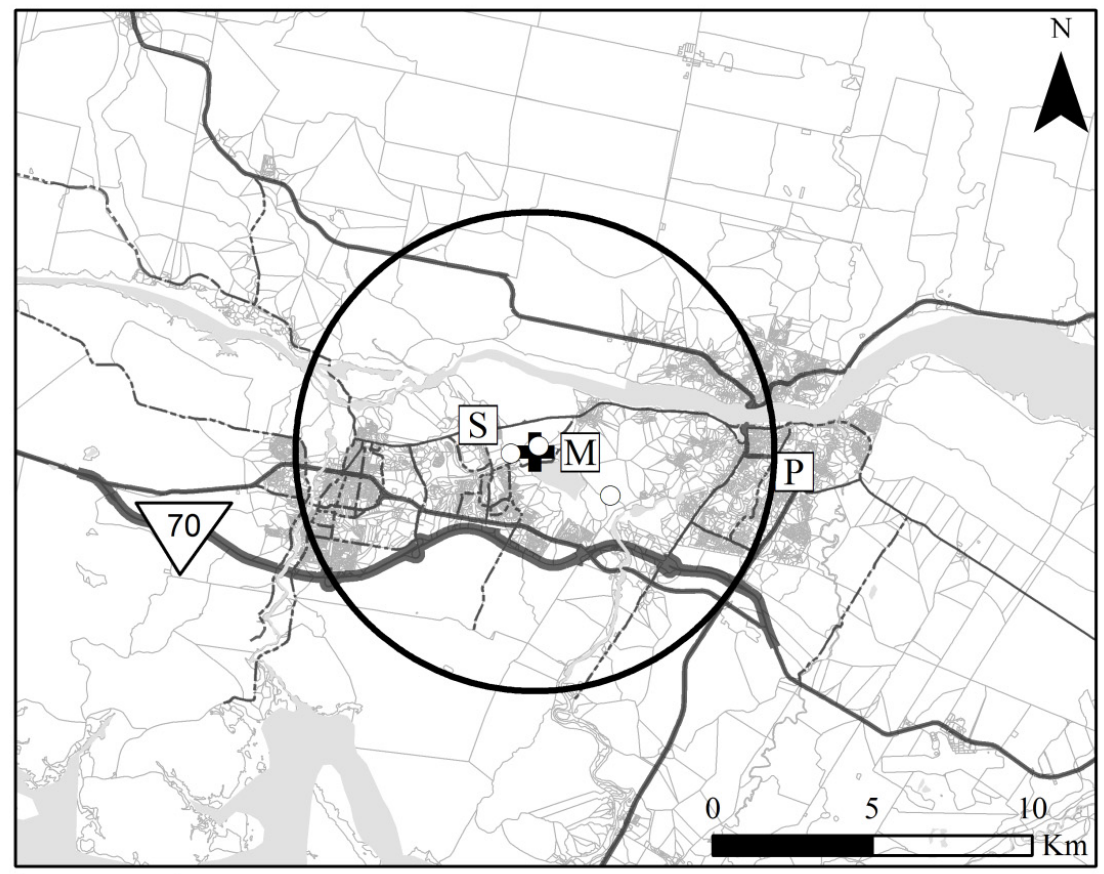

\section{Legend}


Figure 1. Map of an area of $7.5 \mathrm{~km}$ of radius located around an industrial complex comprising an aluminum smelter, where its location has been determinate by a central point located between the three factories, weighted by the quantities of emissions of $\mathrm{SO}_{2}$ and $\mathrm{PM}_{2.5}$ produced by each one of them, in the region of Saguenay, Quebec, Canada 


\subsection{Health Data}

We used hospitalisations that occurred between January $1^{\text {st }} 2001$ and December $31^{\text {th }} 2010$ from the MED-ECHO database, for respiratory conditions in children aged 0 to 4 years, living within $7.5 \mathrm{~km}$ of the industrial complex (i.e. the weighed point between three emissions sources). This particular age group was chosen as it was reported more vulnerable to air emissions in previous studies (Bateson \& Schwartz, 2008). The distance to industry was selected based on previous work in Quebec looking at respiratory hospitalizations near an aluminium smelter which found increased risks of hospitalizations for asthma and bronchiolitis in children aged $2-4$ (Lewin et al., 2013). The database contains the sex of the children, the six digit postal code of the place of residence and the date and the cause of hospitalisation according to the international code of disease version 9 (ICD-9) or version 10 (ICD-10). The respiratory conditions considered were as follows: asthma (ICD-9: 493/ICD-10: J45-J46), bronchiolitis (ICD-9: 466\ICD-10: J21), other respiratory problems (ICD-9: 460-519/ICD-10: J00-J99). Hospitalisations occurring within 30 days of a prior event were discarded.

\subsection{Exposure to Industrial Emissions}

Three exposures variables were used: 1) the daily amount of time that the child's place of residence was downwind of the industrial complex, and the daily mean and maximum concentrations of 2) $\mathrm{SO}_{2}$ and, 3) $\mathrm{PM}_{2.5}$. The daily amount of time that the residence was exposed was computed as follows. We considered that a residence was exposed for an hour if its six digit postal code centroid was located within the area delimited by two angles of 22.5 degrees on both sides of a vector representing the direction of the wind originating from the industrial complex. Figure 1 presents the area of study and the location of the meteorological and pollution monitoring stations. Wind data and other meteorological variables (daily mean temperature, relative humidity and wind speed average) were from a meteorological monitoring station located at approximately $1.5 \mathrm{~km}$ from the industrial complex. The data was obtained from the Data Access Integration (DAI) team, a portal containing environmental data managed by Environment Canada. The number of downwind hours per day was divided by the number of hours with wind direction data available to produce the daily percentage of hours downwind from the industrial complex. Days with less than 18 hours of measurements recorded were discarded from the analyses. For hours with no wind (i.e. $0 \mathrm{~km} / \mathrm{h}$ ), all six digit postal codes centroids located within $2.5 \mathrm{~km}$ of the industrial complex location (as described above) were considered exposed. Daily mean and maximum concentrations of $\mathrm{SO}_{2}$ and $\mathrm{PM}_{2.5}$ were from the National Air Pollution Surveillance (NAPS) program (EC, 2013). The station measuring $\mathrm{SO}_{2}$ with UV fluorescence was located at $1.77 \mathrm{~km}$ from the industrial complex. The $\mathrm{PM}_{2.5}$ levels were measured for a subset of the study period, i.e. 2004 to 2008, with a TEOM sensor with dryer at a station located $8.32 \mathrm{~km}$ away from the industrial complex.

\subsection{Statistical Analyses}

We assessed the association between our three exposure variables (i.e. percent of time downwind, PM2.5 and $\mathrm{SO} 2$ pollution monitors) and hospitalisations for respiratory conditions in children, using a time-stratified case-crossover design, similar to what was done in Lewin et al. (2013). For each case date, control dates were selected by using the same days of the week within the same month as the case date (Lumley \& Levy, 2000). For example if a subject was hospitalized Saturday December 11th 2004, the other Saturdays of the month (December 4, 18, 21) were its control dates. This design allows us to control for secular trends in our hospitalization data (Janes, Sheppard, \& Lumley, 2005; Maclure, 1991).

We performed the analyses for children aged 0 to 4 years and for the 2-4 years subgroup. We also analysed hospitalisations for all respiratory conditions and for asthma and bronchiolitis separately. Analyses were also performed with lag 1 exposure (the day previous to the hospitalisation), and for only those individuals living within $2.5 \mathrm{~km}$ of the industrial complex. Analyses were also performed separately for the two emission point sources of the industrial complex. For these analyses, the hospitalisations considered were those within $7.5 \mathrm{~km}$ of each point source (not within $7.5 \mathrm{~km}$ of the industrial complex).

In order to assess associations between time spent downwind or exposure based on pollution monitors, and hospitalisations for respiratory problems in children, we estimated Odds ratios (OR) with conditional logistic regressions. In the conditional logistic regressions, each case-control date pairs was a strata and the ORs were estimated based on the difference in exposure on case and control days (Rothman, Greenland, and Lash, 2008). We report ORs with their $95 \%$ confidence intervals $(95 \% \mathrm{CI}$ ) based on the inter-quartile range (IQR) of each exposure variable. When case dates were associated with less than three control dates, the strata and related case was removed from our analysis. Associations for our exposure variables were adjusted with the inclusion of daily mean temperature, relative humidity, and average daily wind speed $(\mathrm{km} / \mathrm{h})$ in our logistic regressions. All analyses were performed with the R software (http://www.r-project.org/). 


\section{Results}

During the study period, there were 2909 hospitalizations for respiratory problems in children aged 0 to 4 years old (1 006 for asthma and bronchiolitis). Table 1 details the exposure variables during the study periods. Residences in the study area were downwind from the industrial complex on an average $28.58 \%$ of the time (IQR of 27.24). The daily mean $\mathrm{SO}_{2}$ levels measured during the study period at the monitoring station was 8.91 $\mathrm{ppb}$ with a standard deviation of 14.88 (IQR of $9.22 \mathrm{ppb}$ ). For $\mathrm{PM}_{2.5}$ data only available for the period 2004 to 2008 , the average daily concentration was $5.52 \mu \mathrm{g} / \mathrm{m}^{3}$ (standard deviation of $4.46 \mu \mathrm{g} / \mathrm{m}^{3}$; IQR of $4.03 \mu \mathrm{g} / \mathrm{m}^{3}$ ).

Table 1. $\mathrm{SO}_{2}$ and $\mathrm{PM}_{2.5}$ concentrations and percentage of hours per day that residential postal codes in a buffer of $7.5 \mathrm{~km}$ were downwind of the industrial complex

\begin{tabular}{llllll}
\hline Pollutant & Years of data & Mean & $\begin{array}{l}\text { Standard } \\
\text { Deviation }\end{array}$ & IQR & Number of days of exposition \\
\hline $\begin{array}{l}\text { Percentage of hours } \\
\text { downwind }\end{array}$ & $2001-2010$ & 28.58 & 15.41 & 27.24 & $15025385^{\text {a, b }}$ \\
$\mathrm{SO}_{2}(\mathrm{ppb})$ & $2001-2010$ & 8.91 & 14.88 & 9.22 & 3652 \\
$\mathrm{PM}_{2.5}\left(\mu \mathrm{g} / \mathrm{m}^{3}\right)$ & $2004-2008$ & 5.52 & 4.46 & 4.29 & 578 \\
\hline
\end{tabular}

${ }^{a}$ Number of receptor points 2001-2005: 5077 six-character residential postal codes in the study area $\mathrm{x} 1722$ days of wind data. 25 days were missing wind data.

${ }^{b}$ Number of receptor points 2006-2010 : 5264 six-character residential postal codes in the study area x 1802 days of wind data. 13 days were missing wind data.

Table 2 shows the results of the adjusted associations between hospitalizations for asthma and bronchiolitis in children aged between 0 to 4 years old living in the area of study and the three exposure variables at lag 0 . A statistically significant positive association was found only with the percentage of hours downwind (OR: 1.11; $95 \% \mathrm{CI}=1.01-1.22$, for an IQR of $27 \%$ of daily hours downwind) at lag 0 but large statistical variability was noted for the associations with all three exposure metrics (i.e. percentage of hours downwind and levels of $\mathrm{SO}_{2}$ and $\mathrm{PM}_{2.5}$ ). Results with the percentage of hours downwind were similar at lag 1 (Table A1). Crude and adjusted associations were also similar (Table A2, supplemental material). When analyses were restricted to the small number of children living within $2.5 \mathrm{~km}$ of the industrial complex (Table A3), the association was no longer statistically significant for the percentage of hours downwind and very large statistical variability was noted with all exposure metrics.

Table 2. Adjusted ${ }^{\mathrm{a}}$ associations between hospitalizations for asthma and bronchiolitis in children aged less than 5 years of age, living in a $7.5 \mathrm{~km}$ buffer around the industrial complex and daily exposure variables lag 0

\begin{tabular}{llllll}
\hline \multirow{2}{*}{ Pollutants } & \multirow{2}{*}{$\begin{array}{l}\text { n day } \\
\text { (n case days) }\end{array}$} & IQR (h/day) & OR (95\%CI) & IQR & OR (95\%CI) \\
\cline { 3 - 6 } $\begin{array}{l}\text { Percentage of } \\
\text { hours downwind }\end{array}$ & $4155(957)$ & $27.24 \%(6.48)$ & $1.11(1.01-1.22)$ & N/A & N/A \\
$\mathrm{SO}_{2}(\mathrm{ppb})^{\mathrm{c}}$ & $3967(921)$ & 9.22 & $1.03(0.98-1.08)$ & 47.00 & $1.06(0.98-1.15)$ \\
$\mathrm{PM}_{2.5}\left(\mu \mathrm{g} / \mathrm{m}^{3}\right)^{\mathrm{d}}$ & $1775(415)$ & 4.29 & $0.94(0.84-1.06)$ & 10.00 & $0.97(0.86-1.09)$ \\
\hline
\end{tabular}

${ }^{\mathrm{b}} 16$ cases (i.e., 16 case days +72 control days) were excluded due to missing wind data in case-crossover strata

c 48 cases (i.e., 48 case days +204 control days) were excluded due to missing $\mathrm{SO}_{2}$ concentrations data in case-crossover strata

d 580 cases (i.e., 580 case days +2519 control days) were excluded due to missing $\mathrm{PM}_{2.5}$ concentrations data in case-crossover strata

Associations with $\mathrm{SO}_{2}$ daily levels and with the percentage of hours downwind were slightly more pronounced for children aged 2-4 years of age than for children aged 0 to 4 years (see Table A4 in supplemental material). 
The adjusted $\mathrm{OR}$ for the association with the daily mean $\mathrm{SO}_{2}$ levels was 1.10 per an increase of $9.22 \mathrm{ppb}(95 \%$ CI: $0.98-1.08$ ), and with the daily hourly maximum $\mathrm{SO}_{2}$ levels, it was 1.06 per increase of $47.00 \mathrm{ppb}$ in IQR (95\%CI: 0.98-1.15). Fewer hospitalizations were found in this age group and the statistical variability was high for the associations with $\mathrm{PM}_{2.5}$ levels. No association was noted when hospitalizations for all respiratory symptoms were considered (supplemental material, Table A5).

When associations with hospitalizations for children living within $7.5 \mathrm{~km}$ of the industrial were performed separately for the three emission points instead of within $7.5 \mathrm{~km}$ of the industrial complex (defined as the point between the three emission sources, weighted by total emissions), the results were rather similar to the analyses that were performed using the midpoint of the three emission sources (Table A6 - A8 in supplemental material).

\section{Discussion}

In this study we noted small associations between hospitalisations for bronchiolitis and asthma in children aged less than 5 years old living in proximity to an industrial complex with an aluminum smelter and the daily percentage of hours downwind and $\mathrm{SO}_{2}$ levels at lag 0 and lag 1, although large statistical variability was noted. No association was noted when all respiratory symptoms were included, suggesting that associations were specific to asthma and bronchiolitis and do not include respiratory infections or other respiratory issues.

It is interesting to note that statistically significant results were found between the percentage of hours downwind but not with $\mathrm{SO}_{2}$ and $\mathrm{PM}_{2.5}$ levels measured at monitoring stations. The percentage of hours downwind may capture effects of mixture of pollutants which otherwise may be difficult to assess. Furthermore in remote areas, air pollutant levels are not always monitored and the percentage of hours downwind could be an easy way to assess risks of acute effects in proximity to industrial sources.

Our results are concordant with those of previous studies that assessed the respiratory effects of acute exposure to industrial emissions in children. For example, Aekplakorn et al. (2003) observed in a panel study of Thai children aged 6 to 14 years exposed to air emissions of a coal power station that pulmonary functions inversely decreased with daily particulate levels. Our results can also be compared to those of Lewin et al. (2013), who assessed associations between hospitalisation for asthma in children younger than 5 years old exposed to the emissions of another Quebec aluminum smelter, and who used the same exposure variables as the ones in the present study. Lewin et al. (2013) reported greater risks with the percentage of hours downwind and daily $\mathrm{PM}_{2.5}$, but only for children aged between 2 to 4 years old. While our shorter time period for $\mathrm{PM}_{2.5}$ makes any conclusions on the association with $\mathrm{PM}_{2.5}$ more limited, it is still possible that the difference noted between our study and the one of Lewin et al. (2013) is related to a different composition of the particles emitted by the two industrial complexes.

The estimation of exposure in an epidemiological study performed with secondary data is often difficult. In the present work, we assumed that children were consistently in the area under study and that they were always exposed when the exposure was estimated. These interpretations of the daily reality of the children are likely incorrect in some cases. It is indeed impossible to know if the children were outside or inside their place of residence on a giving day, or if they were always in the study area where the measures of exposure took place. Other limitations include the measures themselves. Even if we used $\mathrm{PM}_{2.5}$ and $\mathrm{SO}_{2}$ measurement located the closest to the residences of the hospitalised children as possible, they were sometimes located kilometers away from the residences. This is a particular concern for the $\mathrm{PM}_{2.5}$ measurement station given that it is located a few hundred meters outside of the study area. Moreover only a few years of $\mathrm{PM}_{2.5}$ data were available for analyses, which limit the reliability of the results with this pollutant in the present study.

In conclusion, our study was designed to estimate the respiratory effects of acute exposure to emissions from an industrial complex with an aluminum smelter complex in young children. Our results support those of previous studies that have shown that the risk of hospitalisation for respiratory problems in young children living in proximity to industrial air emitters increases with air pollutant levels. The use of the percentage of hours per day downwind from an industry appears as a valuable metric to represent exposure in remote areas. Nonetheless improved exposure measures are needed to a better estimate of the risks of respiratory effects associated with acute exposure to industrial emissions like aluminum smelters, as relatively few studies have pertained to this issue.

\section{Competing Interests}

The authors declare that they have no competing interests.

\section{Authors' contributions}

$\mathrm{RL}$ was involved in the modelling, the interpretation of results, and in the writing of the manuscript. $\mathrm{AB}$ was 
involved in data collection, in the interpretation of the results, and in the writing of the manuscript. SB was involved in the interpretation of the results and writing of the manuscript. AS conceived the study, directed the modelling and writing of the manuscript.

All authors reviewed and approved the final manuscript.

\section{Acknowledgement}

"The author(s) would like to acknowledge the Data Access Integration (DA) Team for providing the data and technical support. The DAI Portal (http://climat-quebec.qc.ca/CC-DEV/trunk/index.php/pages/dai) is made possible through collaboration among the Global Environmental and Climate Change Centre (GEC3), the Adaptation and Impacts Research Division (AIRD) of Environment Canada, and the Drought Research Initiative (DRI)."

\section{References}

Aekplakorn, W., Loomis, D., Vichit-Vadakan, N., Shy, C., Wongtim, S., \& Vitayanon, P. (2003). Acute effect of sulphur dioxide from a power plant on pulmonary function of children, Thailand. International journal of epidemiology, 32, 854-861. http://dx.doi.org/10.1093/ije/dyg237

Bateson, T. F., \& Schwartz, J. (2008). Children's response to air pollutants. J. Toxicol. Environ. Health. A, 71, 238-243.

Bertoldi, M. et al. (2012). Health effects for the population living near a cement plant: an epidemiological assessment. Environment international, 41, 1-7. http://dx.doi.org/10.1016/j.envint.2011.12.005

Deger, L. et al. (2012). Active and uncontrolled asthma among children exposed to air stack emissions of sulphur dioxide from petroleum refineries in Montreal, Quebec: A cross-sectional study. Can. Respir. J., 19, 97-102.

Environment Canada. (2013). National Air Pollution Surveillance Network - Data. Retrieved from http://www.ec.gc.ca/air-sc-r/default.asp?lang=En\&n=9547191B-1

Janes, H., Sheppard, L., \& Lumley, T. (2005). Case-crossover analyses of air pollution exposure data: referent selection strategies and their implications for bias. Epidemiology (Cambridge, Mass.), 16, 717-726. http://dx.doi.org/10.1097/01.ede.0000181315.18836.9d

Lewin, A., Buteau, S., Brand, A., Kosatsky, T., \& Smargiassi, A. (2013). Short-term risk of hospitalization for asthma or bronchiolitis in children living near an aluminum smelter. Journal of Exposure Science and Environmental Epidemiology, 23, 474-480. http://dx.doi.org/10.1038/jes.2013.27

Liu, X., Lessner, L., \& Carpenter, D. O. (2012). Association between residential proximity to fuel-fired power plants and hospitalization rate for respiratory diseases. Environmental health perspectives, 120, 807-810. http://dx.doi.org/10.1289/ehp.1104146

Lumley, T., \& Levy, D. (2000). Bias in the case-crossover design: Implications for studies of air pollution. Environmetrics, http://dx.doi.org/10.1002/1099-095X(200011/12)11:6<689::AID-ENV439>3.0.CO;2-N

Maclure, M. (1991). The case-crossover design: a method for studying transient effects on the risk of acute events. Am. J. Epidemiol., 133, 144-153.

Pless-Mulloli, T., Howel, D., \& Prince, H. (2001). Prevalence of asthma and other respiratory symptoms in children living near and away from opencast coal mining sites. International journal of epidemiology, 30, 556-563. http://dx.doi.org/10.1093/ije/30.3.556

Rothman, K. J., Greenland, S., \& Lash, T. L. (2008). Modern Epidemiology (3rd ed). Philadelphia, PA: Lippincott Williams \& Wilkins.

Rusconi, F. et al. (2011). Asthma symptoms, lung function, and markers of oxidative stress and inflammation in children exposed to oil refinery pollution. The Journal of asthma: Official journal of the Association for the Care of Asthma, 48, 84-90. http://dx.doi.org/10.3109/02770903.2010.538106

Smargiassi. A. et al. (2009). Risk of asthmatic episodes in children exposed to sulfur dioxide stack emissions from a refinery point source in Montreal, Canada. Environmental health perspectives, 117, 653-659. http://dx.doi.org/10.1289/ehp.0800010

Statistics Canada. (2012). Census subdivision of Saguenay, V - Quebec. Focus Geogr. Ser. 2011 Census. Retrieved 


\section{Appendix A}

Table A1. Adjusted $^{\text {a }}$ associations between hospitalizations for asthma and bronchiolitis in children aged less than 5 years of age, living in a $7.5 \mathrm{~km}$ buffer around the industrial complex and daily exposure variables at lag 1

\begin{tabular}{llllll}
\hline \multirow{2}{*}{$\begin{array}{l}\text { Pollutants } \\
\text { n day }\end{array}$} & \multicolumn{2}{l}{ Daily mean } & \multicolumn{3}{l}{ Hourly max } \\
\cline { 3 - 6 } & (n case days) & IQR (h/day) & OR (95\%CI) & IQR & OR (95\%CI) \\
\hline $\begin{array}{l}\text { Percentage of } \\
\text { hours downwind }\end{array}$ & $4166(958)$ & $27.24 \%(6.48)$ & $1.18(1.07-1.29)$ & N/A & N/A \\
$\mathrm{SO}_{2}(\mathrm{ppb})^{\mathrm{c}}$ & $3965(918)$ & 9.22 & $0.99(0.94-1.04)$ & 47.00 & $0.97(0.90-1.05)$ \\
$\mathrm{PM}_{2.5}\left(\mu \mathrm{g} / \mathrm{m}^{3}\right)^{\mathrm{d}}$ & $1802(421)$ & 4.29 & $1.02(0.93-1.12)$ & 10.00 & $1.02(0.92-1.14)$ \\
\hline
\end{tabular}

${ }^{\mathrm{b}} 14$ cases (i.e., 14 case days +61 control days) were excluded due to missing wind data in case-crossover strata

c 50 cases (i.e., 50 case days +214 control days) were excluded due to missing $\mathrm{SO}_{2}$ concentrations data in case-crossover strata

d 573 cases (i.e., 573 case days +2491 control days) were excluded due to missing $\mathrm{PM}_{2.5}$ concentrations data in case-crossover strata

Table A2. Crude associations between hospitalizations for asthma and bronchiolitis in children aged less than 5 years of age, living in a $7.5 \mathrm{~km}$ buffer around the industrial complex and daily exposure variables at lag 0

\begin{tabular}{|c|c|c|c|c|c|}
\hline \multirow{2}{*}{ Pollutants } & \multirow{2}{*}{$\begin{array}{l}\text { n day } \\
\text { (n case days) }\end{array}$} & \multicolumn{2}{|l|}{ Daily mean } & \multicolumn{2}{|c|}{ Hourly max } \\
\hline & & IQR (h/day) & OR $(95 \% \mathrm{CI})$ & IQR & OR $(95 \% \mathrm{CI})$ \\
\hline $\begin{array}{l}\text { Percentage of } \\
\text { hours downwind }^{\mathrm{a}}\end{array}$ & $4328(990)$ & $27 \%(6.48)$ & $1.11(1.02-1.22)$ & $\mathrm{N} / \mathrm{A}$ & $\mathrm{N} / \mathrm{A}$ \\
\hline $\mathrm{SO}_{2}(\mathrm{ppb})^{\mathrm{b}}$ & $4174(958)$ & 9.22 & $1.03(0.98-1.08)$ & 47.00 & $1.06(0.99-1.14)$ \\
\hline $\mathrm{PM}_{2.5}\left(\mu \mathrm{g} / \mathrm{m}^{3}\right)^{\mathrm{c}}$ & $1860(426)$ & 4.29 & $0.94(0.84-1.05)$ & 10.00 & $0.96(0.86-1.07)$ \\
\hline
\end{tabular}

${ }^{a} 16$ cases (i.e., 16 case days +72 control days) were excluded due to missing wind data in case-crossover strata

${ }^{\mathrm{b}} 48$ cases (i.e., 48 case days +204 control days) were excluded due to missing $\mathrm{SO}_{2}$ concentrations data in case-crossover strata

c 580 cases (i.e., 580 case days +2519 control days) were excluded due to missing $\mathrm{PM}_{2.5}$ concentrations data in case-crossover strata

Table A3. Adjusted ${ }^{a}$ associations between hospitalizations for asthma and bronchiolitis in children aged less than 5 years of age, living in a $2.5 \mathrm{~km}$ buffer around the industrial complex and daily exposure variables at lag 0

\begin{tabular}{|c|c|c|c|c|c|}
\hline \multirow{2}{*}{ Pollutants } & \multirow{2}{*}{$\begin{array}{l}\text { n day } \\
\text { (n case days) }\end{array}$} & \multicolumn{2}{|l|}{ Daily mean } & \multicolumn{2}{|c|}{ Hourly max } \\
\hline & & IQR (h/day) & OR $(95 \% \mathrm{CI})$ & IQR & OR $(95 \% \mathrm{CI})$ \\
\hline $\begin{array}{l}\text { Percentage of } \\
\text { hours downwind }^{\mathrm{b}}\end{array}$ & $351(80)$ & $27.24 \%(6.48)$ & $0.88(0.59-1.32)$ & N/A & $\mathrm{N} / \mathrm{A}$ \\
\hline $\mathrm{SO}_{2}(\mathrm{ppb})^{\mathrm{c}}$ & $327(75)$ & 9.22 & $1.11(0.91-1.35)$ & 47.00 & $1.18(0.89-1.58)$ \\
\hline $\mathrm{PM}_{2.5}\left(\mu \mathrm{g} / \mathrm{m}^{3}\right)^{\mathrm{d}}$ & $203(46)$ & 4.29 & $1.13(0.75-1.70)$ & 10.00 & $0.97(0.67-1.42)$ \\
\hline
\end{tabular}

\footnotetext{
${ }^{\mathrm{a}}$ Associations are adjusted for relative humidity, wind speed and temperature

b 11 cases (i.e., 11 case days +45 control days) were excluded due to missing wind data in case-crossover strata

c 16 cases (i.e., 16case days +66 control days) were excluded due to missing $\mathrm{SO}_{2}$ concentrations data in case-crossover strata

d 45 cases (i.e., 45case days +192 control days) were excluded due to missing PM $_{2.5}$ concentrations data in case-crossover strata
} 
Table A4. Adjusted associations between hospitalizations for asthma and bronchiolitis in children aged 2 to 4 years old, living in a $7.5 \mathrm{~km}$ buffer around the industrial complex and daily exposure variables at lag 0

\begin{tabular}{|c|c|c|c|c|c|}
\hline \multirow{2}{*}{ Pollutants } & \multirow{2}{*}{$\begin{array}{l}\text { n day } \\
\text { (n case days) }\end{array}$} & \multicolumn{2}{|l|}{ Daily mean } & \multicolumn{2}{|c|}{ Hourly max } \\
\hline & & IQR (h/day) & OR $(95 \% \mathrm{CI})$ & IQR & OR $(95 \% \mathrm{CI})$ \\
\hline $\begin{array}{l}\text { Percentage of } \\
\text { hours downwind }^{\mathrm{b}}\end{array}$ & $1099(251)$ & $27.24 \%(6.48)$ & $1.12(0.93-1.35)$ & N/A & $\mathrm{N} / \mathrm{A}$ \\
\hline $\mathrm{SO}_{2}(\mathrm{ppb})^{\mathrm{c}}$ & $1060(242)$ & 9.22 & $1.10(1.00-1.20)$ & 47.00 & $1.18(1.02-1.37)$ \\
\hline $\mathrm{PM}_{2.5}\left(\mu \mathrm{g} / \mathrm{m}^{3}\right)^{\mathrm{d}}$ & $489(115)$ & 4.29 & $0.89(0.72-1.10)$ & 10.00 & $0.93(0.77-1.13)$ \\
\hline
\end{tabular}

${ }^{\mathrm{a}}$ Associations are adjusted for relative humidity, wind speed and temperature

b 5 cases (i.e., 5 case days +22 control days) were excluded due to missing wind data in case-crossover strata

${ }^{c} 12$ cases (i.e., 12 case days +50 control days) were excluded due to missing $\mathrm{SO}_{2}$ concentrations data in case-crossover strata

d 145 cases (i.e., 145 case days +630 control days) were excluded due to missing $\mathrm{PM}_{2.5}$ concentrations data in case-crossover strata

Table A5. Adjusted ${ }^{\text {a }}$ associations between hospitalizations for all respiratory symptoms in children aged less than 5 years of age, living in a $7.5 \mathrm{~km}$ buffer around the industrial complex and daily exposure variables at lag 0

\begin{tabular}{|c|c|c|c|c|c|}
\hline \multirow{2}{*}{ Pollutants } & \multirow{2}{*}{$\begin{array}{l}\text { n day } \\
\text { (n case days) }\end{array}$} & \multicolumn{2}{|l|}{ Daily mean } & \multicolumn{2}{|c|}{ Hourly max } \\
\hline & & IQR (h/day) & OR $(95 \% \mathrm{CI})$ & IQR & OR $(95 \% \mathrm{CI})$ \\
\hline $\begin{array}{l}\text { Percentage of } \\
\text { hours downwind }^{\mathrm{b}}\end{array}$ & $12077(2771)$ & $27.24 \%(6.48)$ & $1.01(0.96-1.07)$ & $\mathrm{N} / \mathrm{A}$ & $\mathrm{N} / \mathrm{A}$ \\
\hline $\mathrm{SO}_{2}(\mathrm{ppb})^{\mathrm{c}}$ & $11551(2668)$ & 9.22 & $1.02(0.99-1.05)$ & 47.00 & $1.06(1.01-1.11)$ \\
\hline $\mathrm{PM}_{2.5}\left(\mu \mathrm{g} / \mathrm{m}^{3}\right)^{\mathrm{d}}$ & $5057(1170)$ & 4.29 & $0.95(0.89-1.03)$ & 13.00 & $0.97(0.91-1.05)$ \\
\hline
\end{tabular}

${ }^{\mathrm{a}}$ Associations are adjusted for relative humidity, wind speed and temperature

${ }^{b} 41$ cases (i.e., 41 case days +184 control days) were excluded due to missing wind data in case-crossover strata

${ }^{\mathrm{c}} 131$ cases (i.e., 131 case days +552 control days) were excluded due to missing $\mathrm{SO}_{2}$ concentrations data in case-crossover strata

d 1700 cases (i.e., 1700 case days +7411 control days) were excluded due to missing PM $_{2.5}$ concentrations data in case-crossover strata

Table A6. Adjusted ${ }^{\mathrm{a}}$ associations between hospitalizations for asthma and bronchiolitis in children aged less than 5 years of age, living in a $7.5 \mathrm{~km}$ buffer around the point source B and daily exposure variables at lag 0

\begin{tabular}{llllll}
\hline Pollutants & n day & \multicolumn{2}{l}{ Daily mean } & \multicolumn{2}{l}{ Hourly max } \\
\cline { 3 - 6 } & (n case days) & IQR (h/day) & OR (95\%CI) & IQR & OR (95\%CI) \\
\hline $\begin{array}{l}\text { Percentage of } \\
\text { hours downwind }\end{array}$ & $4133(952)$ & $27.24 \%(6.48)$ & $1.11(1.01-1.21)$ & N/A & N/A \\
$\mathrm{SO}_{2}(\mathrm{ppb})^{\mathrm{c}}$ & & & & & \\
$\mathrm{PM}_{2.5}\left(\mu \mathrm{g} / \mathrm{m}^{3}\right)^{\mathrm{d}}$ & $1767(413)$ & 4.29 & $1.03(0.98-1.08)$ & 47.00 & $1.06(0.98-1.15)$ \\
\hline
\end{tabular}

${ }^{a}$ Associations are adjusted for relative humidity, wind speed and temperature

${ }^{\mathrm{b}} 16$ cases (i.e., 16 case days +72 control days) were excluded due to missing wind data in case-crossover strata

${ }^{c} 48$ cases (i.e., 48 case days +204 control days) were excluded due to missing $\mathrm{SO}_{2}$ concentrations data in case-crossover strata

d 577 cases (i.e., 577 case days +2505 control days) were excluded due to missing $\mathrm{PM}_{2.5}$ concentrations data in case-crossover strata 
Table A7. Adjusted ${ }^{\text {a }}$ associations between hospitalizations for asthma and bronchiolitis in children aged less than 5 years of age, living in a $7.5 \mathrm{~km}$ buffer around the point source $\mathrm{A}$ and daily exposure variables at lag 0

\begin{tabular}{llllll}
\hline Pollutants & \multirow{2}{*}{$\begin{array}{l}\text { n day } \\
\text { (n case days) }\end{array}$} & Daily mean & \multicolumn{3}{l}{ Hourly max } \\
\cline { 3 - 6 } & & IQR (h/day) & OR $(95 \% \mathrm{CI})$ & IQR & OR (95\%CI) \\
\hline $\begin{array}{l}\text { Percentage of } \\
\text { hours downwind }\end{array}$ & $4127(951)$ & $27.24 \%(6.48)$ & $1.09(0.99-1.20)$ & N/A & N/A \\
$\mathrm{SO}_{2}(\mathrm{ppb})^{\mathrm{c}}$ & & & & & \\
$\mathrm{PM}_{2.5}\left(\mu \mathrm{g} / \mathrm{m}^{3}\right)^{\mathrm{d}}$ & $17937(914)$ & 9.22 & $1.03(0.98-1.08)$ & 47.00 & $1.07(0.99-1.16)$ \\
\hline
\end{tabular}

${ }^{a}$ Associations are adjusted for relative humidity, wind speed and temperature

${ }^{\mathrm{b}} 15$ cases (i.e., 15 case days +68 control days) were excluded due to missing wind data in case-crossover strata

${ }^{\mathrm{c}} 48$ cases (i.e., 48 case days +204 control days) were excluded due to missing $\mathrm{SO}_{2}$ concentrations data in case-crossover strata

d 582 cases (i.e., 582 case days +2526 control days) were excluded due to missing $\mathrm{PM}_{2.5}$ concentrations data in case-crossover strata

Table A8. Adjusted ${ }^{\mathrm{a}}$ associations between hospitalizations for asthma and bronchiolitis in children aged less than 5 years of age, living in a $7.5 \mathrm{~km}$ buffer around the point source $\mathrm{C}$ and daily exposure variables at lag 0

\begin{tabular}{|c|c|c|c|c|c|}
\hline \multirow[t]{2}{*}{ Pollutants } & \multirow{2}{*}{$\begin{array}{l}\text { n day } \\
\text { (n case days) }\end{array}$} & \multicolumn{2}{|l|}{ Daily mean } & \multicolumn{2}{|c|}{ Hourly max } \\
\hline & & IQR (h/day) & OR $(95 \% \mathrm{CI})$ & IQR & OR $(95 \% \mathrm{CI})$ \\
\hline $\begin{array}{ll}\text { Percentage of } \\
\text { hours } \\
\text { downwind }^{\mathrm{b}}\end{array}$ & $4190(966)$ & $27.24 \%(6.48)$ & $1.09(0.99-1.19)$ & $\mathrm{N} / \mathrm{A}$ & N/A \\
\hline $\mathrm{SO}_{2}(\mathrm{ppb})^{\mathrm{c}}$ & 3998 (927) & 9.22 & $1.02(0.97-1.07)$ & 47.00 & $1.04(0.97-1.13)$ \\
\hline $\mathrm{PM}_{2.5}\left(\mu \mathrm{g} / \mathrm{m}^{3}\right)^{\mathrm{d}}$ & $1802(420)$ & 4.29 & $0.95(0.84-1.07)$ & 10.00 & $1.00(0.89-1.13)$ \\
\hline
\end{tabular}

${ }^{\mathrm{a}}$ Associations are adjusted for relative humidity, wind speed and temperature

${ }^{\text {b }} 18$ cases (i.e., 18 case days +80 control days) were excluded due to missing wind data in case-crossover strata

${ }^{c} 51$ cases (i.e., 51 case days +206 control days) were excluded due to missing $\mathrm{SO}_{2}$ concentrations data in case-crossover strata

${ }^{\mathrm{d}} 586$ cases (i.e., 582 case days +2537 control days) were excluded due to missing $\mathrm{PM}_{2.5}$ concentrations data in case-crossover strata

\section{Copyrights}

Copyright for this article is retained by the author(s), with first publication rights granted to the journal.

This is an open-access article distributed under the terms and conditions of the Creative Commons Attribution license (http://creativecommons.org/licenses/by/3.0/). 